\title{
THE Role of RaW MATERIAL Management IN PRODUCTION OPERATIONS
}

\author{
OLUSAKIN S AKINDIPE \\ DEPARTMENT OF BUSINESS ADMINISTRATION \\ IGBAJO POLYTECHNIC \\ P. M. B. 303, IGBAJO, OSUN STATE, NIGERIA \\ PHONE NO.: +2348035709270
}

\begin{abstract}
Experience had shown that there is critical operational problem regarding raw material management in manufacturing organisations. This has prompted the desire to embark on a conceptual analysis that will examine the problem and strive to proffer useful suggestions. This paper intends to bring to the fore, the salient issue of inefficiency in the practice of raw material management and its effects on production operations of manufacturing concerns by theoretical review. The paper concludes that, should practitioners become proactive by applying proffered solutions, efficiency will be achieved in management of raw materials and production operations.
\end{abstract}

\section{KEYWORDS}

Raw Material Management, Inventory Management, Production Operation, Manufacturing Organisations.

\section{INTRODUCTION}

The importance of raw material to efficient operation of a manufacturing organisation cannot be over emphasized; in that the availability of the raw material in the right quality and quantity will determine to a reasonable extent; the availability, quality and quantity of the resultant output.

Raw material management is critical to the overall performance of any manufacturing concern. Beside demand and other forces like competitor's actions and general price index; raw material situation in terms of efficient management and effective planning determines the activity level, the turn-over and the ultimate profit in a given company. The determination of economic order quantity (EOQ), re-order level and minimum/maximum stock levels is important in raw material management in any manufacturing outfit.

The material function is assumed to be organised and operated on an integrated basis and is also presumed to be responsible for material forecasting, planning, inventory control, scrap control and disposal; providing management information regarding purchases and inventories within the framework of the financial policies and norms. A glance at these functions will reveal the intricacies involved in maintaining balanced policies on raw material management.

Material management being the coordination of efforts (planning, controlling, organising, directing) towards achieving efficiency in the procurement, transportation, stocking and

DOI: $10.5121 /$ ijmvsc.2014.5303 
utilization of inputs of a manufacturing organisation is therefore central to production activities and management. Effective and efficient functioning of the material management has direct bearing on the total performance of the organisation. The management of raw material in a manufacturing organization therefore deserves attention and critical study in order to achieve uninterrupted production runs and enhanced performance in operations (Khalid, 2008). Besides, holding the right stock level could improve the level of available working capital that could be profitably employed in other areas. These objectives could only be achieved through integrated approach to material management functions by combining planning, procurement and inventory control.

\section{LITERATURE REVIEW \\ 2.1 RELATIONSHIP BETWEEN INVENTORY AND RAW MATERIAL}

Inventory refers to totality of stocks, being held by a business enterprise at a particular time. The following groups of inventory are of concern to managers in manufacturing organisations:

1 Raw materials,

2 In-progress or semi finished goods,

3 Finished goods.

4 Other stocks such as: tools, spare parts and production consumables.

Raw materials are component parts of the stock of inventories carried by a manufacturing firm at a given time. Every organisation has inventories of some type and the economics and techniques of inventory management are critical for efficient operation, profitability and survival; especially in a highly competitive environment (Kros, Falasca \& Nadler, 2006).

Inventory control is the science- based art of controlling the amount of stock held in various forms within a business (Lewis, 1970). Inventory control is a method of recording and reporting the movement of raw materials within a company: from material stock room, through any of the manufacturing processes to the finished product stage. According to Sharif (2011) inventory management basically aims at providing both internal and external customers with the required service levels in terms of quality, quantity and order fill rate, to ascertain present and future requirements for all types of inventory to avoid overstocking while avoiding bottleneck in production and to keep costs to a minimum.

\subsection{Classification OF INVENTORY MANAGEMENT SySTEM}

The use of inventory management system in raw material management practice is imperative today; given the dynamic nature of operations in the frequently changing world of business. Mantho (1994) classified Inventory Management computer based activities into three broad areas:

1 Inventory record keeping: due to the availability of computers at a reasonable price, SMEs have found it appropriate to automate their inventory records through computerization.

2 Inventory decision-making: many models can be integrated into computer based inventory systems.

3 Material requirement planning (MRP) system: MRP is an Inventory Management (IM) information system concerned with getting the right materials to the right place at the right time. 
However, modern Inventory Management systems are more challenging because of several variables. According to Sharif (2011), in a fluid IM environment; these factors include high inflation rates at certain periods, low availability of traditional materials, high costs of labour leading to less making and more buying, increasing numbers of suppliers entering the procurement market and rapid development of micro-processors and software in decisionmaking support systems. In addition, new technological innovations lead to the development of substitutes (for example, smart materials replacing steel and aluminum), which add to the challenges for IM (Mohanty, 1985).

\subsection{IMPORTANT ELEMENTS IN RAW MATERIAL MANAGEMENT}

Purchasing and inventory control are the key elements for efficient material management. Decisions on how much to buy and when to buy cannot be view in isolation; as is being done in many quarters. The provision of safety stock on the other hand is a kind of insurance and is largely influenced by the lead time required to procure the materials. It is obvious that any improvement in the lead time would necessitate a decrease in the volume of safety stock and thereby reduce overall capital lock-up in inventory (Saeed, 2008).

Another important issue in material management is the matter of maintaining good systems and procedures and this calls for strict discipline in documentation. This implies that all related paper work are completed in time so as to generate the basic data and compile timely and reliable information for planning, follow-up and control. This seems mandatory, be it manual or computerized system. The success of the system calls for cooperation and understanding of all that are concerned for providing timely, the necessary data; in order to ensure that the information processed for action reflects the realities of the situation. According to Nasiri, Davoudpour and Karimi (2010) resource planning and timely information for decision, action and control is possible today with the support of a computer system with the relevant application package and software. An integrated material management system with electronic data processing support avoids many of the common volume data in a short time span and checking the actual against the preset norms, so as to take quick preventive and/or corrective actions.

\subsection{CONCEPTUAL FRAMEWORK}

In a work of this nature, a conceptual analysis of relevant studies on the problem under consideration is desirable; given the universal perception and the enormity of the challenges that raw material management had posed to manufacturers (Marcello, Andrea \& Montanari, 2004).

\section{Material Management Problem: Aged and Global}

Providing a clue to what material management problem was, Dear (1989) gave the following assertions: that the most common reason by far for a manager becoming interested in inventory is when he finds out he has more of it than he should have. He went further that in a spare part operation, management became interested in the first place because the combined branch stockholding was in excess of budget. Over- stocking as identified above is not the only problem in material management. Under-stocking could lead to a bigger problem as analyzed by the same writer. "How do managers react?

- They order those in charge to reduce stock, with the result that ordering on suppliers is cut back drastically. The situation quickly changes from one of adequate cover of moving lines with 
a considerable excess of non moving stock to one of very inadequate cover of moving lines with a considerable excess of non moving stock" (Dear,1989). In his analysis of problems relating to material management, Dear observed that management formulate inventory policies that are not applicable in their areas of operations. Therefore, he advised: "Inventory control should be systematic, i.e. they are based on an objective set of rules or guidelines that are in accord with the company objectives".

Another notable contributor on the subject of consideration is Simeon (1990) who gave credence to the enormity of raw material management problem when he wrote: "for batch manufacturing companies, stock control is a major factor in managing production efficiency and on-time delivery, not to mention the havoc it can play with cash flow". He went further to assert that delay in meeting customers' order could be result of poor management of materials.

Macbeth (1989) believes that adequate staff development programmes must focus upon purchasing as tasks and responsibilities and the way in which good supply performance helps to sharpen the competitive edge.

Rajeev (2008) made a study of forty small and medium enterprises (SMEs) in Bangalore, India and observed that even in an inventory intensive manufacturing industry sector, Inventory Management (nay, material management) practices were poor. He went further that the use of formal practices for managing inventories was also inadequate. According to him, poor material management practices were characterized by a lack of an integrated approach in the form of the absence of links between physical stock and accounting system. A lack of appreciation for Inventory Management (IM) among the entrepreneurs and the lack of qualified staff were the two major factors contributing to low Inventory Management practices (Muhammad, Razi \& Tarn, 2003). This situation was complicated further by other factors such as constraints on working capital, a lack of progress in the area of HRD and the organizational characteristics of the SMEs (Baker, 2007). The use of a formal inventory ordering policy, such as fixed quantity ordering or fixed period ordering policy was not observed in the SMEs. Instead, a random policy was followed by the SMEs for material procurement. The study also identified the use of rule of thumb for IM, a low importance given to forecasting and random ordering for material procurement, low level use of computers and a low level of importance given to purchasing and variable lead-time.

The inventory management (IM) practices of small and medium scale enterprises in Finland and Greece were studied by Chikan and Whybark, (1990) to identify the experiences of managers concerning IM. In Finland, 15 case studies of IM were undertaken, including examining the role of IM in corporate planning, inventory decision-making and performance measurement. The findings revealed that IM decisions are made at the operational level with minimal guidance from the top. Furthermore, the lack of accurate, real-time and suitable aggregate information of material flows and stock levels prevented these enterprises from setting precise quantitative goals for IM. Furthermore, financial pressures were identified as forcing the enterprises to reduce their inventories, which eventually led to internal as well as external stock outs (Chikan \& Whybark, 1990).

Given the fore-goings, it is clear that the problem of material management is age long and people had; over the years attempted to seek solution. The solution offered by Townsend (1992) is in what he termed "the standard requisition concept" which he said could be achieved through: 
1 Determination of order quantity and stock level, to be controlled and managed;

2 Anticipation of workloads. This enables a realistic level of planning to be completed to prevent a stock-out situation.

Dear (1989) suggests "an adaptive method of forecasting" by setting safety stocks in terms of a desired service (stock) level under management control using one of the adaptive available algorithms.

Todd (1990) asserted that the problem started with the implementation of material management systems. He believes that material management will be successful if its implementation is one, which is designed to provide the real benefit. As antidote to the problems of implementation, he prescribed the following rules:

1 The implementation should be considered as a tactical and strategically business improvement.

2 Implementation should concentrate on people not the systems.

3 Determine a long-term vision of future to provide a focus for real business benefits.

4 The project must have a full time project manager reporting to a multi-disciplined executive management.

5 An educational plan must be constructed in line with software and computer system plans.

6 Before the system goes to live, the base data must be audited and achieve an acceptable level of accuracy.

He concluded: don't under-estimate the amount of education needed including that of those who "ought to know".

\subsection{Nature of Raw Material Management Problem in the Nigerian MANUFACTURING SECTOR}

There are critical problems associated with raw material management in manufacturing organizations in Nigeria today. These are rarely given adequate attentions due to inability of people involved to trace the problems to raw material management.

This writer had in an empirical study traced the following problems to inefficiency in raw material/inventory management in Nigeria:

1 The inefficient use of production time, labour and other resources due to delays or incessant short down and interruptions during production have become inherent part of operations in many manufacturing organization in Nigeria. This often led to inability to meet customers' order and eventual loss of market shares. Low capacity utilization and loss of revenue as consequence of these problems led to closure of many manufacturing firms in the country.

2 The poor liquidity position of many manufacturing concerns in Nigeria is a matter of concern to many shareholders and stakeholders alike. To hold too much stock than necessary will lead to capital lock-up in inventory of raw materials. The materials held idle in stores have values attached to them; and the likelihood is that the organization will never regain the money in them if they become obsolete and useless. 
3 In many manufacturing concerns in Nigeria, there is inadequate provision of good quality manpower in stock maintenance and material management. This is indeed, a serious issue since employees are those charged with the responsibility of monitoring progress and reporting impending insufficiency. They are to ensure that stocks are properly kept and protected against fire and other disaster or loss. The "people" are to ensure efficient use of warehouse facilities and space; keep proper and adequate records (Akindipe, 2005).

\subsection{TOWARDS EFFICIENCY IN MATERIAL MANAGEMENT}

Despite that the Nigerian situation is slightly different from that of the rest of the world, particularly the advanced economies where business organisations are IT compliance; within a different socio-cultural and more literate environment, the same suggestions could be applicable in similar circumstances. To this end, the following recommendations are proffered specifically to ensure efficiency in the practice of raw material management in Nigeria and other parts of the globe:

1. It is recommended that manufacturing organisations should always determine the minimum level of stock to carry. This is to ensure that stock-out or sudden unavailability is forestalled. With the removal of stock-out, other banes such as loss of production time, low capacity utilization, and inability to meet production targets will be removed.

2. That manufacturing organisations make raw material plans and schedules such that arrival of raw material and other inventories is programmed to ensure that there is no delay between requisition time and the time of supply. This will prevent production operations from being disrupted and as such low capacity utilization and inability to meet production targets will be addressed.

3. All slow-moving stock items should be identified; their time of need noted to ensure that the maintenance of such item stops immediately. All obsolete items should be sold to recoup capital lock up in them. Acquisition of obsolete items could be removed by being aware of trends in the technological and business environments. Over-stocking could be forestalled by having clear definition of maximum stock level. An adherence to recommendations on slowmoving stock, obsolete items and over-stocking would ensure that tied-up fund that could be useful as working capital is available. In this way, liquidity positions of manufacturing organisations will be better.

4. Employment of stack illiterates as store workers should be stopped as it results in problems such as misplacement and dislocation of vital documents, files and stock items. In areas where higher stock management education is not required, (like stock keeping and records) employee should be given adequate orientation and training. There should also be training and retraining of employees to ensure that they are kept abreast of developments in the field.

5. The use of electronic data processing devices will go a long way in removing the problem of inability to use inventory models. Lack of knowledge of the use of quantitative values to produce information is the major hindrance in model application by store personnel. 
International Journal of Managing Value and Supply Chains (IJMVSC) Vol.5, No. 3, September 2014

\section{CONCLUSION}

Although the situation being experienced in the practice of raw material/inventory management today is to say the least, disheartening; given the poor level of computerization, the degree of inability in the use of models for inventory decision making, the involvement of illiterates and non experts in the management of raw materials and inventory; the prospects for improvement are evident.

This however, is hinged on the preparedness of managers of manufacturing organisations to be responsive to suggestions from within the business and the academic communities and take steps towards achieving efficiency in the practice of raw material management. Having this done, the prevailing problems of incessant stoppage of production, low level of capacity utilization, inability to meet production targets, poor liquidity and other identified problems will be addressed.

\section{REFERENCES}

1. Akindipe, S. O. (2005). Raw materials management and inventory control in manufacturing organization. Unpublished Masters Thesis, University of Ado-Ekiti, Nigeria.

2. Chikan, A. \& Whybark, (1990). Cross-national comparison of production and inventory management practices. Engineering Costs and Production Economics, (19), 149-56.

3. Dear, A. (1989). Improvement in management and control of inventory, purchasing and supply management. Journal of the Institute of Purchasing \& Supply Management, $1(5), 15-19$.

4. Khalid, S. (2008). Trend forecasting for stability in supply chains. Journal of Business Research (61), 1113-1124.

5. Kros, J. F., Falasca, M. \& Nadler, S. S. (2006). Impact of just-in-time inventory systems on OEM suppliers. Industrial Management \& Data Systems, 106(2), 224-241.

6. Lewis, C. D. (1970). Scientific inventory control. London: Bottleworth Ltd.

7. Macbeth, D. (1989). Not purchasing but supply chain management. Purchasing \& supply management. Journal of the Institute of Purchasing \& Supply 1(9), 11-20.

8. Mantho, V. (1994). Concepts and applications of inventory management in northern Greece. International Journal of Production Economics, (35), 149-52.

9. Marcello, B., Andrea G. \& Roberto, M. (2004). Multi-attribute classification method for spare parts inventory management. Journal of Quality in Maintenance Engineering, $10(1), 55-65$.

10. Mohanty, R. P. (1985). Inventory problems under multiple constraints: some studies. Engineering Costs and Production Economics, (9), 355-92.67.

11. Nasiri, G. R., Davoudpour, H. \& Karimi, B. (2010). The impact of integrated analysis on supply chain management: A coordinated approach for inventory control policy. Supply Chain Management: An International Journal, 15(4), 277 - 289.

12. Rajeev, N. (2008). Inventory management in small and medium enterprises: A study of machine tool enterprises in Bangalore. Management Research News, 31( 9), 659-669. 
International Journal of Managing Value and Supply Chains (IJMVSC) Vol.5, No. 3, September 2014

13. Sharif, (2011). A comparison of purchase and inventory management system of two educational institutes. IEOM (163), 1056-1066.

14. Simon, Mallin. (1990). Fast and effective stock management, purchasing \& supply management. Journal of the Institute of Purchasing \& Supply Management, 6(9), 3-8.

15. Todd, R. (1990). Implementing a material management system logistics: Purchasing \& supply management. Journal of the Institute of Purchasing \& Supply, 1(4), 7-21.

16. Townsend, R. (1992). Material management in the NHS logistics: Purchasing \& supply management: Journal of the Institute of Purchasing \& Supply Management, 1(3), 13-24.

17. Peter, B. (2007). An exploratory framework of the role of inventory and warehousing in international supply chains. International Journal of Logistics Management, 18 (1), 6480 .

18. Razi, M. A., \& Tarn, F. M. (2003). An applied model for improving inventory management in ERP system, Logistics Information Management, 16(2), 114-124.

\begin{abstract}
Author
Olusakin Akindipe is a seasoned Management consultant, Administrator and Teacher. A member of the Nigerian Institute of Management, he holds a master's degree in Business Administration. His wealth of experience over the years at various positions in the industry and in teaching qualifies him a reliable source on Production Management topics. He is currently a lecturer, Head of Department of Business Administration and Ag. Dean, faculty of Management studies Igbajo Polytechnic, Igbajo, Osun state, Nigeria.
\end{abstract}

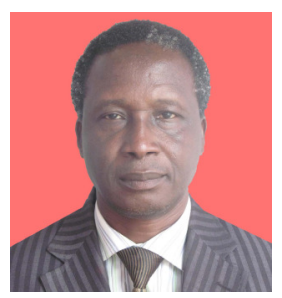

